\title{
Ácidos graxos como marcadores biológicos da ingestão de gorduras
}

\author{
Fatty acids as biological markers of fat intake
}

\author{
Juliana dos Santos VAZ1 \\ Fabíola DEBONI² \\ Mirela Jobim de AZEVEDO 3,4 \\ Jorge Luiz GROSS 4,5 \\ Themis ZELMANOVITZ3,4,5
}

\section{RES U M O}

Os ácidos graxos da dieta têm sido associados ao desenvolvimento de doenças crônicas. Os inquéritos alimentares, utilizados em estudos clínicos e epidemiológicos para estimativa da ingestão de nutrientes, apresentam limitações na coleta de informações. Nesse sentido, a utilização da composição de ácidos graxos do plasma e do tecido adiposo como marcadores do tipo de gordura alimentar pode fornecer uma medida mais acurada da ingestão de gorduras. Esta pesquisa tem como objetivo evidenciar aspectos metabólicos de alguns ácidos graxos e o papel como marcadores da ingestão de gorduras, e apresentar as técnicas analíticas empregadas na sua determinação. A biópsia do tecido adiposo, com determinação da composição de ácidos graxos, fornece uma informação a longo prazo da ingestão de gorduras, enquanto que a avaliação da composição das frações lipídicas séricas representa a ingestão a curto e médio prazos. Os ácidos graxos essenciais, os ácidos graxos saturados com número ímpar de carbonos (15:0 e 17:0) e os ácidos graxos trans, por não apresentarem síntese endógena, são utilizados como marcadores biológicos da ingestão de gorduras ou de sua própria ingestão. As principais técnicas utilizadas para a determinação de ácidos graxos são a cromatografia gasosa e a cromatografia líquida de alta precisão. No presente momento, o uso de marcadores biológicos para a ingestão de gorduras, associados aos inquéritos alimentares, representa a forma mais completa de avaliação da ingestão de gorduras.

Termos de indexação: ácidos graxos; dieta; lipídeos; marcadores biológicos; tecido adiposo.

\footnotetext{
$\overline{1}$ Mestranda, Programa de Pós-Graduação em Ciências Médicas: Endocrinologia, Universidade Federal do Rio Grande do Sul. Porto Alegre, RS, Brasil.

2 Acadêmica, Curso de Nutrição, Faculdade de Medicina, Universidade Federal do Rio Grande do Sul. Porto Alegre, RS, Brasil.

3 Programa de Pós-Graduação em Ciências Médicas: Endocrinologia, Universidade Federal do Rio Grande do Sul. Porto Alegre, RS, Brasil.

4 Departamento de Medicina Interna, Faculdade de Medicina, Universidade Federal do Rio Grande do Sul. Porto Alegre, RS, Brasil.

5 Serviço de Endocrinologia, Hospital de Clínicas de Porto Alegre. Rua Ramiro Barcelos, 2350, Prédio 12, 4ªndar, 90035-003, Porto Alegre, RS, Brasil. Correspondência para/Correspondence to: T. ZELMANOVITZ. E-mail: $<$ themis@voyager.com.br>.
} 


\title{
A B S T R A C T
}

\begin{abstract}
Dietary fatty acids have been associated with the development of chronic diseases. The methods commonly used in dietary assessment for estimating nutrient intake in clinical and epidemiological studies present limitations regarding data collection. The use of plasma and adipose tissue fatty acid composition as markers of the type of fat ingested has been studied and can provide a more accurate measurement of dietary fat intake. The aim of this study is to evidence the metabolic aspects of some fatty acids and their role as markers of dietary fat intake, and to present the analytical methods used in their determination. Analysis of the fatty acid composition of adipose tissue provides long-term information on dietary fat intake, whereas the determination of the fatty acid composition of serum lipid fractions accounts for the short- and medium-term dietary intakes. The essential fatty acids, the saturated fatty acids with an odd number of carbon atoms (15:0 and 17:0) and the trans fatty acids are used as biological markers of dietary fat intake or of these individual components, since they are not synthesized endogenously. Gas chromatography and high-performance liquid chromatography are the main analytical methods used to determine fatty acid composition. At present, the most comprehensive evaluation of dietary fat intake comprises the determination of biological markers in association with dietary assessment methods.
\end{abstract}

Indexing terms: fatty acids; diet; lipids; biological markers; adipose tissue.

\section{N T R O D U ÇÃ O}

O consumo de ácidos graxos (AG) tem sido associado ao desenvolvimento de doenças crônicas, como diabetes mellitus ${ }^{1}$, câncer ${ }^{2} \mathrm{e}$ doenças cardiovasculares ${ }^{3,4}$. Em estudos clínicos e epidemiológicos, a avaliação da ingestão alimentar de nutrientes, em especial a ingestão de gorduras, é geralmente realizada por meio de métodos de inquérito alimentar, como os questionários de freqüência alimentar (QFA), registros alimentares (RA) e recordatórios de 24 horas. Apesar de serem técnicas práticas e simples, os inquéritos nutricionais são métodos de análise indireta da dieta e sujeitos a limitações na coleta de informações e conseqüente super e/ou sub-registro ${ }^{5}$.

Uma maneira de avaliar a fidedignidade das informações fornecidas por esses métodos é compará-los a medidas objetivas, como o uso de marcadores biológicos da ingestão de nutrientes. Esses marcadores são representados por componentes da dieta que refletem a absorção de nutrientes e não apresentam síntese endógena. Os marcadores biológicos fornecem uma medida mais acurada, comparados aos inquéritos nutricionais, por não serem afetados por vieses de memória, vieses do entrevistador e erro na estimativa da ingestão alimentar ${ }^{6}$.
A estimativa da ingestão absoluta de gordura total por meio de marcadores biológicos não é disponível até o momento. Entretanto, existem marcadores que podem ser utilizados para quantificar modificações na ingestão de gordura ${ }^{7,8}$, assim como marcadores que refletem o consumo de $A G$ essenciais e de $A G$ não essenciais sem produção endógena ${ }^{9-11}$.

A composição de $A G$ do plasma e do tecido adiposo tem sido empregada como instrumento na avaliação objetiva do tipo de gordura consumida pelos indivíduos ${ }^{9-11}$. Este trabalho visa evidenciar aspectos metabólicos dos ácidos graxos e seu papel como marcadores da ingestão alimentar de gorduras em estudos clínicos e epidemiológicos, e apresentar as técnicas analíticas empregadas na sua determinação, em tecidos e fluidos biológicos.

\section{Metabolismo dos ácidos graxos}

\section{Absorção e transporte intracelular de ácidos graxos}

Cerca de 95\% da composição de gordura da dieta é representada por triacilgliceróis (TG), sendo o restante constituído por outras formas de lipídeos, como fosfolipídeos, AG livres, colesterol e fitosteróis. O processo de digestão e absorção 
dos lipídeos é complexo, iniciando no estômago e passando pelo intestino delgado, no qual ocorre parte principal da digestão e a absorção. A borda em escova dos enterócitos no intestino delgado é o sítio inicial da absorção dos monoglicerídeos e diglicerídeos, produtos da digestão lipídica no lúmen intestinal.

O processo de absorção, metabolismo intracelular e liberação na circulação dos AG presentes no lúmen intestinal varia conforme o tamanho da cadeia carbônica. Após a absorção, os AG de cadeia média e curta são conduzidos diretamente via sangüínea para o fígado ${ }^{12,13}$. Já os AG de cadeia longa, em sua quase totalidade, são ressintetizados a TG no interior dos enterócitos, formando os quilomícrons, os quais, através do sistema linfático, atingem a circulação sangüínea ${ }^{14}$. Apesar da absorção dos AG de cadeia longa poder ocorrer por meio de difusão rápida através da membrana celular, quando presentes em altas concentrações, evidências reforçam a presença de um sistema de transporte composto por proteínas de membrana transportadoras que atuam em baixas concentrações do substrato. Tais proteínas aumentam a captação de AG de cadeia longa. Entre elas, inclui-se as FATP (fatty acid transport protein), as FABP (fatty acid binding protein) e a fatty acid translocase ${ }^{15,16}$.

A família das FATP, até o momento, é composta por seis membros identificados, que se expressam com um padrão característico nos diferentes tecidos que metabolizam os AG. A FATP4 é a única FATP que se expressa no intestino delgado e apresenta um papel importante na captação dos AG de cadeia longa pelos enterócitos ${ }^{15}$.

Nos enterócitos também estão presentes as proteínas ligantes dos AG, conhecidas como FABP. As FABP são especialmente responsáveis pelo transporte e distribuição intracelular dos AG de cadeia longa, com uma possível participação na absorção dos AG. Nos enterócitos, as FABP também possuem papel importante no armazenamento dos AG de cadeia longa não-esterificados. São co-fatores de várias enzimas do metabolismo lipídico e participam da modulação dos sinais intracelulares mediados por lipídeos, do crescimento e da diferenciação celular ${ }^{17}$. O intestino, assim como outros tecidos com alta taxa de metabolismo, captação e armazenamento dos $A G$ (fígado, adipócito e músculos), apresenta altos níveis de FABP relacionados ao fluxo e utilização dos AG. A distribuição na mucosa intestinal das FABPs intestinais e hepáticas (principais FABPs que atuam no intestino) evidencia seu papel na captação e transporte intracelular dos AG da dieta ${ }^{17}$. Um alto conteúdo de lipídeos da dieta é capaz de provocar aumento dos níveis de FABP gastrointestinal, sendo esse aumento maior no duodeno, menor no jejuno e praticamente ausente no íleo ${ }^{18}$. Entretanto, não é clara a associação entre o tipo e o conteúdo de lipídeos da dieta e a expressão dessas proteínas nos enterócitos ${ }^{19}$. A presença de mutação do gene da FABP intestinal, com mudanças funcionais dessa proteína, pode resultar em maior ligação e transporte de AG e conseqüente secreção de TG pelas células intestinais ${ }^{20}$. Além disso, estudos clínicos têm demonstrado uma associação entre a presença de mutação do gene do FABP intestinal e maior insulinemia, resistência insulínica, índice de massa corporal, aumento dos níveis de LDL-colesterol, apoproteína B100 e TG séricos no jejum ${ }^{21,22}$.

\section{Transporte de ácidos graxos no plasma}

O transporte dos AG é composto pelas vias metabólicas exógena e endógena. A via exógena, que caracteriza a fase pós-absortiva, representa o transporte do intestino para o fígado. A via endógena é composta pelo transporte das lipoproteínas sintetizadas nos hepatócitos, do fígado para os tecidos periféricos, assim como dos adipócitos para os tecidos periféricos ${ }^{14}$.

Na fase pós-absortiva (via-exógena), quando os quilomícrons atingem a circulação sanguínea, sofrem a ação da Lipase de Lipoproteína (LPL), que provoca a hidrólise dos TG que os compõem e cujo produto são AG e gliceróis. Esses AG são utilizados pelos tecidos periféricos ou 
armazenados nos adipócitos. O teor de TG dos quilomícrons vai se reduzindo, formando, então, os remanescentes dos quilomícrons que são, finalmente, captados nos hepatócitos ${ }^{23}$. A via endógena dos AG provenientes dos adipócitos ou do fígado caracteriza a fase de jejum. Os AG livres, provenientes dos adipócitos, são transportados no plasma principalmente pela albumina, até os tecidos periféricos, nos quais são oxidados para fornecer energia ${ }^{24}$. Os $A G$ esterificados ( $T G$, ésteres de colesterol, fosfolipídeos e outros), provenientes principalmente do fígado, são transportados pelas lipoproteínas very low density lipoprotein (VLDL) e, em menor proporção, pelas low density lipoprotein (LDL) e high density lipoprotein (HDL)4. As VLDL são, essencialmente, formadas no fígado e exercem papel fundamental no transporte endógeno dos AG sob a forma de TG. Os TG das VLDL são hidrolisados pela LPL, gerando as remanescentes de VLDL ou intermediary density lipoprotein (IDL) ${ }^{25}$. As IDL podem ser removidas da circulação ou, após a ação da LPL, originar as LDL. As LDL fazem parte da via metabólica das lipoproteínas ricas em colesterol, e são responsáveis pela distribuição do colesterol para os tecidos extra-hepáticos ${ }^{26}$. As HDL exercem papel fundamental no transporte reverso do colesterol, removendo o excesso desse nos tecidos periféricos e o transportando para o fígado, no qual é metabolizado e eliminado na forma de ácidos e sais biliares ${ }^{27}$.

\section{Síntese de ácidos graxos}

A maioria dos AG pode ser sintetizada pelo organismo, sofrer processos de elongação (inserção de pares de carbonos) e/ou dessaturação da cadeia de carbonos (inserção de ligação dupla). Os processos de elongação da cadeia geralmente ocorrem no retículo endoplasmático. Já as dessaturações ocorrem, primariamente, no peroxissomo, por meio das enzimas dessaturases ${ }^{28}$.

Em relação às famílias n-7 e n-9, os AG precursores $C 16: 0$ e C18:0, sofrem dessaturação pela delta 9 dessaturase, formando os AG monoinsaturados 16:1n-7 (AG palmitoléico) e 18:1n-9 (AG oléico) ${ }^{28}$, respectivamente. A partir desses AG monoinsaturados, pelos processos de dessaturação e elongação, são formados Os $A G$ poliinsaturados (AGPI) das respectivas famílias. Já os AGPI precursores das famílias n-3 e n-6, o ácido $\alpha$-linolênico e o ácido linoléico, respectivamente, são definidos como AG essenciais, por não serem sintetizados endogenamente nos seres humanos e em alguns animais, devido à carência de enzimas dessaturases, que são capazes de inserir ligação dupla entre os carbonos 3-4 e 6-7, assim como de enzimas hidrogenases capazes de remover tais insaturações. Esses AG são sintetizados, exclusivamente, pelo reino vegetal ${ }^{4}$.

Os AGPI essenciais podem ser modificados pelos mamíferos, com alongamento da cadeia, inserção de insaturações e descarboxilação de pares da cadeia. Dessa forma, os AG das famílias $n-3, n-6$ e n-9 competem entre si, especialmente na etapa de dessaturação pela dessaturase delta 6. Em geral, as enzimas dessaturases apresentam maior afinidade para os substratos de maior insaturação. Outra competição dos AGPI é pelas enzimas elongases e pelas acil transferases, envolvidas na formação dos fosfolipídeos. A existência de tais competições interfere no metabolismo dos AGPI essenciais. O excesso do AG linoléico pode reduzir a síntese de metabólitos do ácido linolênico (18:3 n-3), como o ácido eicosapentanóico (C20:5n-3) ${ }^{29}$.

Os produtos do metabolismo (elongação e dessaturação) dos AG essenciais serão sempre da mesma família desses substratos. Portanto, os ácidos eicosapentaenóico (EPA C20:5 n-3) e docosahexaenóico (DHA C22:6n-3), são produtos do metabolismo do ácido $\alpha$-linolênico (18:3n-3), assim como o ácido araquidônico (C20:4 n-6) é o produto do metabolismo do ácido linoléico (18:2 $\mathrm{n}-6)$ (Figura 1) ${ }^{4}$.

Finalmente, após os processos de absorção, transporte intracelular e plasmático e síntese, os AG serão utilizados como fonte de energia, na estrutura de membranas e, no caso dos AG essenciais, como precursores de eicosanóides. Os AG também serão importantes em uma série de sistemas fisiológicos, e como mediadores das respostas imune e inflamatória. 
Ácido $\alpha$ - Linolênico (18:3 n-3)

delta6 dessaturase

$18: 4 n-3$

elongase

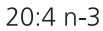

delta5 dessaturase

Ácido Eicosapentaenóico (EPA 20:5 n-3)

elongase

Docosapentaenóico (DPA 22:5 n-3)

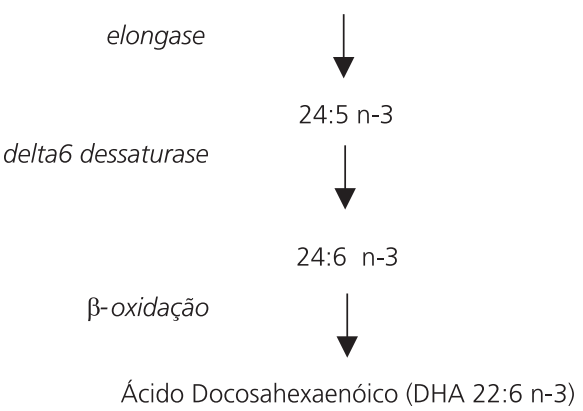

Figura 1. Metabolismo dos ácidos graxos essenciais. Adaptado de Leonard et al. ${ }^{48}$.

\section{Ácidos graxos como marcadores biológicos}

A composição de AG do tecido adiposo relaciona-se, a longo-prazo, com a ingestão dietética ${ }^{30}$, enquanto que a dos lipídeos séricos representa uma medida a curto e médio prazo, de semanas a meses ${ }^{7}$. Medida de AG em adipócitos, provenientes de biópsias de tecido adiposo subcutâneo de indivíduos normais, apresenta boa correlação com a ingestão dos mesmos na dieta, avaliada tanto a partir de QFA ${ }^{9,11}$ como de RA com ${ }^{11,31,32}$ e sem pesagem de alimentos ${ }^{33}$. Essa associação é especialmente mais significativa, quando analisada a ingestão de $A G$ essenciais ${ }^{9,11,33}$ e AG saturados (AGS) provenientes de produtos lácteos (principalmente os AG com número ímpar de carbonos: 15:0 e 17:0) ${ }^{31,32}$, que não são sintetizados endogenamente. Quanto aos AG monoinsaturados geralmente não é observada

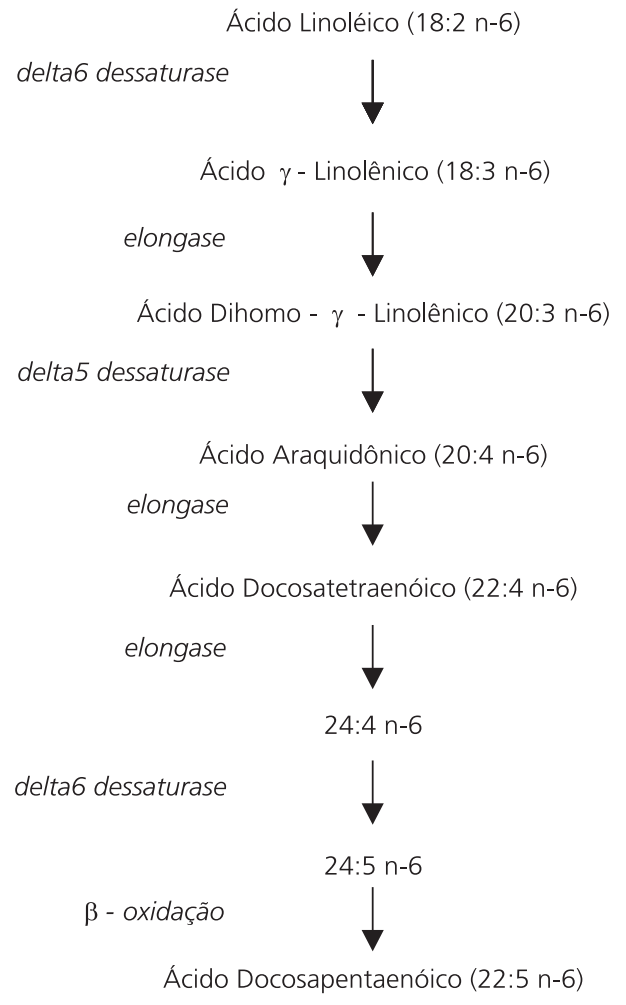

correlação entre a medida no sangue e no tecido adiposo com a dieta, presumivelmente, por serem AG que podem ser sintetizados endogenamente. A realização de biópsia de tecido adiposo, entretanto, é pouco factível para estudos epidemiológicos ou com grande número de pacientes. Já a coleta de sangue para a análise de lipídeos séricos é mais simples e melhor aceita pelos participantes de estudos ${ }^{34}$.

\section{Ácidos graxos essenciais}

A utilização dos ácidos graxos essenciais, que são ácidos graxos poliinsaturados, como marcadores biológicos do consumo de gorduras, é de grande relevância pois esses não são sintetizados pelos seres humanos e, sobretudo, por terem um papel fundamental na saúde. Nesse sentido, os AGPI, em especial os da série n-3, 
tanto no tecido adiposo 9,11,31 quanto em lipídeos séricos ${ }^{9,10}$ têm sido estudados.

Em indivíduos saudáveis, Tjonneland et al. ${ }^{11}$ observaram uma correlação positiva entre os AGPI do tecido adiposo e os da dieta, especialmente quando esta foi avaliada por intermédio de RA, com pesagem de alimentos. Andersen et al. ${ }^{9}$, também, avaliando indivíduos saudáveis, observaram correlação fraca entre o QFA e os AG linoléico, $\alpha$-linolênico, EPA e DHA tanto no tecido adiposo $(r=0,38, r=0,42, r=0,52, r=0,49$, respectivamente) quanto nos lipídeos séricos totais $(r=0,16, r=0,28, r=0,51$ e $r=0,52$, respectivamente). Os maiores valores de correlação do EPA e do DHA, quando comparados aos AG linoléico e $\alpha$-linolênico, provavelmente, ocorram devido ao fato de os primeiros não estarem sujeitos a processos metabólicos como dessaturação, enlongação, esterificação e oxidação, como ocorre com seus precursores. Além disso, os ácidos graxos EPA e DHA já podem ser consumidos pré-formados na alimentação.

Um estudo holandês, realizado com indivíduos obesos com diabetes mellitus tipo 2, também demonstrou correlação positiva entre o conteúdo de EPA e DHA no tecido adiposo e os seus conteúdos na dieta, analisada por RA de três dias realizados a cada dois meses ao longo de dois anos. Os autores concluíram que, em pacientes obesos com diabetes mellitus tipo 2, uma única biópsia de tecido adiposo reflete a informação a longo prazo da ingestão dietética de EPA e DHA ${ }^{33}$.

Os AG nas frações séricas de fosfolipídeos e ésteres de colesterol também têm sido estudados como marcadores da ingestão dietética. Durante o estudo ARIC (Atherosclerosis Risk in Communities) foi analisada a dieta habitual de 3570 indivíduos saudáveis utilizando-se um QFA semi-quantitativo com 66 itens. Foram observadas correlações positivas entre os AGS e os AGPI das frações éster de colesterol e fosfolipídeos e os seus conteúdos na dieta, entretanto com valores de correlações fracas, entre 0,20 e 0,4434. Por outro lado, Kobayashi et al. ${ }^{10}$, analisando os AG dos fosfolipídeos séricos como marcadores biológicos da ingestão dietética de 87 homens normais de origem japonesa, encontraram valores de correlação de maior magnitude, mas somente para a série $n-3$. Essa análise foi realizada durante as estações do inverno e do verão, e os valores das correlações foram, respectivamente: AGPI n-3 pré-formados: $r=0,61$ e $r=0,60$; EPA: $r=0,70$ e $r=0,63$; docosapentaenóico (DPA): $r=0,45$ e $r=0,46$ e DHA: $r=0,44$ e $r=0,46$. A presença de correlações mais fortes nesse estudo, quando comparado com o estudo ARIC, provavelmente, se deve à elevada ingestão de AGPI na dieta da população japonesa, principalmente pelo consumo de produtos marinhos ricos em AGPI da série n-3.

Conclui-se que os AGPI pré-formados, especialmente os da série n-3, apresentam significativa correlação com o seu conteúdo na dieta e podem ser utilizados como marcadores biológicos da ingestão desse tipo de gordura.

\section{Ácidos graxos saturados}

Devido à associação entre a maior ingestão de AGS e doença cardiovascular, existe interesse especial no estudo de marcadores biológicos da ingestão de AGS na dieta, sejam esses no tecido adiposo ou nos lipídeos séricos. Os ácidos pentadecanóico (15:0) e heptadecanóico (17:0), por serem sintetizados apenas pelos animais ruminantes, e presentes na alimentação humana a partir dos produtos lácteos e das carnes de ruminantes, têm sido foco de análise como marcadores de ingestão alimentar ${ }^{31,35}$

Em estudo realizado com homens saudáveis de Uppsala, na Suécia, Wolk et al. ${ }^{31}$ observaram correlações significativas entre o conteúdo dos AG 15:0, 17:0 do tecido adiposo, com a ingestão desses AG. Posteriormente, Smedman et al. ${ }^{35}$ também demonstraram correlação entre a ingestão de gordura total de produtos lácteos e a proporção de AG 15:0 nas frações de éster de colesterol e fosfolipídeos 
séricos. Esses resultados sugerem que, em populações nas quais o consumo de produtos lácteos é elevado, os conteúdos dos AG 15:0 e 17:0 no tecido adiposo e do AG 15:0 nas frações séricas de éster de colesterol e fosfolipídeos, servem como marcadores da sua ingestão na dieta e refletem a ingestão de gordura láctea total.

Devido ao conteúdo importante do ácido mirístico (14:0) na gordura do leite, Wolk et al. ${ }^{32}$ analisaram também o conteúdo deste AG nas frações séricas de fosfolipídios e ésteres de colesterol e no tecido adiposo em 114 homens suecos. Os autores observaram correlação significativa entre o conteúdo do AG 14:0 da dieta, proveniente dos produtos lácteos, e o seu conteúdo no tecido adiposo, enquanto as correlações com esse AG nas frações séricas de éster de colesterol e fosfolipídios foram também significativas, porém menores.

Em conclusão, as medidas do AG 14:0 no tecido adiposo e dos AG 15:0 e 17:0 no tecido adiposo e nos lipídeos séricos, podem ser utilizadas como marcadores de sua ingestão proveniente de produtos lácteos e de carnes de animais ruminantes, especialmente em populações com maior ingestão desses produtos.

\section{Ácidos graxos trans}

O emprego de gordura vegetal hidrogenada na fabricação de alimentos trouxe um aumento no consumo de AG trans na dieta moderna. Estudos epidemiológicos têm mostrado efeito deletério dos AG trans no perfil lipídico sérico (aumento na razão LDL/HDL) ${ }^{36}$ e conseqüente risco aumentado para doença cardiovascular ${ }^{37}$. Como não existe síntese endógena de $A G$ trans, esses AG também podem ser utilizados como marcadores da ingestão de alimentos específicos que são fontes desses $A G$, como, por exemplo, derivados do leite ou de gordura vegetal hidrogenada. Baylin et al. ${ }^{38}$ observaram, a partir da correlação entre conteúdo de AG trans no tecido adiposo e ingestão alimentar, que os melhores indicadores para a ingestão total de $A G$ trans foram o ct18:2 n-6 e tc18:2 n-6 ( $r=0,58$ para ambos), seguido do total de $t 18: 1(r=0,45)$ e $t 16: 1 \quad(r=0,16)$, após ajuste para idade, sexo, índice de massa corporal e fumo. Foi também demonstrado que a correlação positiva entre o conteúdo de AG trans na dieta e no tecido adiposo foi maior com os $A G$ trans de fonte vegetal, do que com os AG trans de origem animal $(0,27 \text { vs. } 0,08)^{39}$. Portanto, os AG trans do tecido adiposo podem ser utilizados como marcadores biológicos, evidenciando, indiretamente, os conteúdos de alimentos oriundos de leite e derivados e/ou da gordura vegetal parcialmente hidrogenada que compõem a dieta.

No Quadro 1 são apresentados os principais estudos de correlação entre ácidos graxos da dieta e ácidos graxos séricos e do tecido adiposo. Embora a técnica de avaliação da ingestão alimentar seja diferente entre os estudos, assim como outros fatores, como etnia, número de indivíduos estudados, tempo de acompanhamento, presença ou não de morbidades associadas (por exemplo, diabetes mellitus), observou-se que as correlações chegam até 0,7 . Deve ser lembrado que uma boa correlação não significa uma concordância absoluta entre as variáveis analisadas. Nesse sentido, a utilização dos AG séricos e do tecido adiposo, como marcadores biológicos da ingestão de gorduras, não nos permite uma quantificação precisa da ingestão desses mesmos $A G$, mas complementa de forma objetiva as informações fornecidas pelos inquéritos alimentares quanto à ingestão de gorduras, especialmente a ingestão dos AGPI e dos AGS provenientes de produtos lácteos. Além disso, modificações da composição desses AG séricos podem ser usadas eficientemente, para avaliar modificações introduzidas na dieta, servindo como um instrumento de medida de adesão às intervenções dietéticas.

\section{Métodos de análise dos ácidos graxos em tecidos e fluidos biológicos}

A análise da composição de AG pode ser realizada nos eritrócitos, plaquetas, tecido adiposo, 
496 | J.S. vAZ et al.

Quadro 1. Estudos de correlação entre ácidos graxos da dieta e séricos e de ácidos graxos da dieta e do tecido adiposo.

\begin{tabular}{|c|c|c|c|c|}
\hline Estudo & Inquérito alimentar & Local de medida do ácido graxo & Ácido graxo analisado & r \\
\hline \multirow[t]{3}{*}{ Andersen et al. ${ }^{9}$} & RA 7 dias & tecido adiposo & AGPI & 0,57 \\
\hline & & & EPA & 0,44 \\
\hline & & & DHA & 0,55 \\
\hline \multirow[t]{3}{*}{ Kobayashi et al..$^{10}$} & 12 RA 3 dias & tecido adiposo & AGPI & 0,50 \\
\hline & & & EPA & 0,66 \\
\hline & & & DHA & 0,55 \\
\hline \multirow[t]{6}{*}{ Tjonneland et al..11 } & QFA & tecido adiposo & AGPI & 0,34 \\
\hline & & & EPA & 0,52 \\
\hline & & & DHA & 0,49 \\
\hline & & lipídeos séricos totais & AGPI & 0,20 \\
\hline & & & EPA & 0,51 \\
\hline & & & DHA & 0,52 \\
\hline \multirow[t]{4}{*}{ Wolk et al. ${ }^{31}$} & QFA & fração fosfolipídeo sérica & AGPI & 0,25 \\
\hline & & & EPA & 0,20 \\
\hline & & & DHA & 0,42 \\
\hline & & & AGS & 0,15 \\
\hline \multirow[t]{4}{*}{ Wolk et al. ${ }^{32}$} & RA 7 dias & fração éster de colesterol sérica & AGPI & 0,31 \\
\hline & & & EPA & 0,23 \\
\hline & & & DHA & 0,42 \\
\hline & & & AGS & 0,23 \\
\hline \multirow[t]{11}{*}{ Popp-Snijders et al. ${ }^{33}$} & 4 RA 1 semana & fração fosfolipídeo sérico: & AGPI n-3 & 0,61 \\
\hline & & - inverno & EPA & 0,70 \\
\hline & & & DPA & 0,45 \\
\hline & & & DHA & 0,44 \\
\hline & & & AGPI n-3 & 0,60 \\
\hline & & - verão & EPA & 0,63 \\
\hline & & & DPA & 0,46 \\
\hline & & & DHA & 0,46 \\
\hline & & tecido adiposo & $15: 0$ & 0,61 \\
\hline & & & $17: 0$ & 0,40 \\
\hline & & & $15: 0+17: 0$ & 0,60 \\
\hline \multirow[t]{2}{*}{ Ma et al. ${ }^{34}$} & RA 7 dias & fração éster de colesterol sérica & $15: 0$ & 0,46 \\
\hline & & fração fosfolipídeo sérico & & 0,34 \\
\hline \multirow[t]{3}{*}{ Smedman et al. ${ }^{35}$} & RA & fração éster de colesterol sérica & & 0,34 \\
\hline & & fração fosfolipídeo sérico & $14: 0$ & 0,30 \\
\hline & & tecido adiposo & & 0,64 \\
\hline \multirow[t]{4}{*}{ Baylin et al. ${ }^{38}$} & QFA & tecido adiposo & $c t 18: 2 n-6$ & 0,58 \\
\hline & & & tc18:2 n-6 & 0,58 \\
\hline & & & $t 18: 1$ & 0,45 \\
\hline & & & $t 16: 1$ & 0,46 \\
\hline
\end{tabular}

r= coeficiente de Pearson; RA= registro alimentar; QFA= questionário de freqüência alimentar; $A G P I=$ ácidos graxos poliinsaturados; EPA= ácido eicosapentaenóico; DHA= ácido docosahexaenóico; AGPI n-3= ácidos graxos poliinsaturados da série n-3; DPA= ácido docosapentaenóico; AGS= ácidos graxos saturados; 15:0 ácido pentadecanóico; 17:0 ácido heptadecanóico; 14:0 ácido mirístico; ct18:2 n-6= cis, trans 18:2 n-6; tc18:2 $\mathrm{n}-6=$ trans, cis $18: 2 \mathrm{n}-6 ; t 18: 1=$ trans $18: 1 ; t 16: 1=$ trans $16: 1$.

lipídeos totais do plasma e em subfrações lipídicas (ésteres de colesterol, triglicerídeos e fosfolipídeos) do plasma. Para a medida dos AG do tecido adiposo de seres humanos, a amostra é comumente aspirada das regiões glútea ou abdominal, podendo haver diferença entre as concentrações de $A G$ dos sítios ${ }^{40}$.

O preparo da amostra depende do tipo de tecido e fração a ser analisada. O método para extração dos lipídeos totais séricos comumente 
empregado utiliza a solução de Folch (clorofórmio/metanol 2:1), que se baseia na diferença de solubilidade dos lipídeos nos solventes ${ }^{41}$. Quando a dosagem dos $A G$ for realizada nas frações lipídicas séricas (ésteres de colesterol, triglicerídeos e fosfolipídeos), utiliza-se a cromatografia de camada delgada para a separação das mesmas. Essa etapa é trabalhosa e demorada, e não é necessária para a determinação dos AG nos lipídeos totais. De uma maneira geral, a medida dos AG nos lipídeos totais pode ser utilizada em vez das frações, já que os $A G$ nas frações se correlacionam com os AG nos lipídeos totais ${ }^{42}$.

A etapa seguinte é a determinação dos AG individuais, e os métodos comumente empregados são a cromatografia gasosa (CG) e cromatografia líquida de alta precisão (CLAP) ${ }^{43}$. Entretanto, para a identificação dos AG é necessária sua derivatização. Dependendo do método de análise utilizado, CG ou CLAP, diferentes formas de derivatização podem ser utilizadas. No primeiro, os métodos de derivatização são a transesterificação das ligações dos $A G$ ou a esterificação dos AG livres. Em CLAP, utiliza-se a saponificação, exceto na análise de $A G$ que requerem também transesterificação $0^{44}$. Geralmente, para a análise dos AG livres necessita-se de temperaturas maiores do que para a análise dos ésteres metílicos ${ }^{45}$.

A escolha entre a CG e a CLAP está relacionada à precisão quantitativa, volatilidade dos $A G$ analisados e ao custo. A CG é o método mais comumente empregado, devido ao menor custo, embora a CLAP seja o método mais sensível ${ }^{44}$. A CLAP é um tipo de cromatografia líquida cuja coluna tem capacidade de realizar separações e análises quantitativas de grande quantidade de compostos ${ }^{44}$. Na CG, após a preparação da amostra, essa é injetada em coluna polar (ou iônica) e sofre partição cromatográfica de seus ésteres metílicos, que são volatilizados e detectados por meios que convertem a concentração do componente na fase gasosa em sinal elétrico, o qual é amplificado e registrado de forma gráfica. A volatilização dos ésteres ocorre em tempos diferentes, definidos como tempos de retenção, que são determinados pelo número de carbonos e pela posição das duplas ligações.

Para a identificação dos AG, comparam-se os tempos de retenção de cada AG da amostra com os de uma solução padrão. Há duas formas de calibração do padrão, que são escolhidas de acordo com o tipo de análise desejada. Para a análise qualitativa, a calibração externa é utilizada, injetando-se soluções padrões de AG conhecidos de várias concentrações e construindo-se gráficos com os tempos de retenção padronizados para cada AG. Com a curva de retenção dos $A G$ do padrão, identificam-se os $A G$ na amostra analisada. Os resultados das concentrações de cada AG identificado na amostra são expressos como percentual da área total. Já para a análise quantitativa, utiliza-se a calibração interna, adicionando-se à construção do padrão uma quantidade conhecida de um AG que não esteja presente na amostra a ser analisada, geralmente um AG com número ímpar de carbono (C13:0, 17:0, 19:0 e 23:0). Na construção do gráfico de referência, relaciona-se a razão da concentração de cada padrão com a concentração do padrão interno. $\mathrm{Na}$ amostra também se adiciona a mesma quantidade do padrão interno e, pela razão das áreas obtidas no cromatograma, pode-se obter a concentração de cada $A G^{45}$.

$\mathrm{Na}$ identificação de isômeros trans, de ocorrência natural em gordura dos ruminantes e obtidos a partir da hidrogenação de óleos vegetais, pode ocorrer sobreposição dos sinais dos isômeros trans e cis, como, por exemplo, do C18:1 (metil elaídico 9t-18:1 e o metil oléico 9c-18:1) no espectrofotômetro, comprometendo a determinação do conteúdo desses isômeros ${ }^{43,46,47}$. Portanto, para a melhor resolução na identificação de isômeros trans, exige-se o emprego de colunas capilares de 100 metros, ou ainda a combinação da cromatografia de camada fina impregnada com nitrato de prata com a CG $\mathrm{CG}^{43,46,47}$.

\section{O N CLUS Ã O}

A ingestão de gorduras pode ser avaliada por meio de inquéritos alimentares e de marca- 
dores biológicos, estes visualizados na composição de ácidos graxos séricos e/ou no tecido adiposo. As medidas dos ácidos graxos essenciais e/ou seus metabólitos (DHA e EPA), de alguns ácidos graxos saturados (15:0 e 17:0) provenientes de produtos lácteos e dos ácidos graxos trans, tanto no tecido adiposo quanto no plasma, refletem de forma adequada o seu conteúdo na ingestão alimentar. Esses ácidos graxos séricos constituem-se nos marcadores biológicos de eleição para utilização em pesquisa clínica e epidemiológica, devido à sua relativa praticidade.

Entre as técnicas analíticas empregadas na determinação dos ácidos graxos em tecidos e fluidos biológicos, a cromatografia líquida de alta precisão (CLAP) é a mais sensível. Entretanto, devido ao custo, a cromatografia gasosa (CG) é a mais utilizada.

Em conclusão, as informações fornecidas pelos inquéritos alimentares, combinadas com a identificação dos marcadores biológicos, constituem a forma ideal de avaliação da ingestão de gorduras da dieta.

\section{A GRADECIMENTOS}

JSV é bolsista da Coordenação de Aperfeiçoamento de Pessoal de Nível Superior. FD foi bolsista da Fundação de Amparo à Pesquisa do Estado do Rio Grande do Sul. Um reconhecimento especial à farmacêutica Magda Susana Perassolo, pelas suas contribuições e revisão sobre as técnicas empregadas na análise dos ácidos graxos.

\section{REFERÊ N CIAS}

1. Thanopoulou AC, et al. Dietary fat intake as risk factor for the development of diabetes. Diabetes Care. 2003; 26(2):302-7.

2. Rose DP. Dietary fatty acids and cancer. Am J Clin Nutr. 1997; 66(Suppl 4):998S-1003S.

3. Hu FB, Cho E, Rexrode KM, Albert CM, Manson JE. Fish and long-chain w-3 fatty acid intake and risk of coronary heart disease and total mortality in diabetic women. Circulation. 2003; 107(14): 1852-7.
4. Schaefer EJ. Lipoproteins, nutrition, and heart disease. Am J Clin Nutr. 2002; 75(2):191-212.

5. Westerterp KR, Goris $A H$. Validity of the assessment of dietary intake: problems of misreporting. Curr Opin Clin Nutr Metab Care. 2002; 5(5):489-93.

6. Potischman N. Biologic and methodologic issues for nutritional biomarkers. J Nutr. 2003; 133(Suppl 3):875S-80.

7. Katan MB, Deslypere JP, van Birgelen AP, Penders $M$, Zegwaard $M$. Kinetics of the incorporation of dietary fatty acids into serum cholesteryl esters, erythrocyte membranes, and adipose tissue: an 18-month controlled study. J Lipid Res. 1997; 38(10):2012-22.

8. Zock PL, Mensink RP, Harryvan J, de Vries JH, Katan MB. Fatty acids in serum cholesteryl esters as quantitative biomarkers of dietary intake in humans. Am J Epidemiol. 1997; 145(12): 1114-22.

9. Andersen LF, Solvoll K, Johansson LR, Salminen I, Aro A, Drevon CA. Evaluation of a food frequency questionnaire with weighed records, fatty acids, and alpha-tocopherol in adipose tissue and serum. Am J Epidemiol. 1999; 150(1):75-87.

10. Kobayashi M, Sasaki S, Kawabata T, Hasegawa K, Akabane M, Tsugane S. Single measurement of serum phospholipid fatty acid as a biomarker of specific fatty acid intake in middle-aged Japanese men. Eur J Clin Nutr. 2001; 55(8):643-50.

11. Tjonneland A, Overvad K, Thorling E, Ewertz M. Adipose tissue fatty acids as biomarkers of dietary exposure in Danish men and women. Am J Clin Nutr. 1993; 57(5):629-33.

12. Berk PD, Bradbury M, Zhou SL, Stump D, Han NI. Characterization of membrane transport processes: lessons from the study of BSP, bilirubin, and fatty acid uptake. Semin Liver Dis. 1996; 16(2):107-120.

13. Trotter PJ, Ho SY, Storch J, Fatty acid uptake by Caco-2 human intestinal cells. J Lipid Res. 1996; 37(2):336-46

14. Spector AA. Plasma lipid transport. Clin Physiol Biochem. 1984; 2(2-3):123-34.

15. Pohl J, Ring A, Hermann T, Stremmel W. Role of FATP in parenchymal cell fatty acid uptake. Biochim Biophys Acta. 2004; 1686(1-2):1-6.

16. Haunerland $\mathrm{NH}$, Spener F. Fatty acid-binding proteins: insights from genetic manipulations. Prog Lipid Res. 2004; 43(4):328-49.

17. Storch J, Thumser AE. The fatty acid transport function of fatty acid-binding proteins. Biochim Biophys Acta. 2000; 1486(1):28-44. 
18. Ockner RK, Manning JA. Fatty acid-binding protein in small intestine. Identification, isolation, and evidence for its role in cellular fatty acid transport. J Clin Invest. 1974; 54(2):326-38.

19. Drozdowski L, Clement L, Keelan M, Niot I. Dietary lipids modify intestinal lipid-binding protein RNA abundance in diabetic and control rats. Digestion. 2004; 70(3):192-8.

20. Hegele RA. A review of intestinal fatty acid binding protein gene variation and the plasma lipoprotein response to dietary components. Clin Biochem. 1998; 31(8):609-12.

21. Baier L, Sacchettini JC, Knowe WC, Eads J, Paolisso G, Tatarini PA, et al. An amino acid substitution in the human intestinal fatty acid binding protein is associated with increased fatty acid binding, increased fat oxidation and insulin resistance. J Clin Invest. 1995; 95(3):1281-7.

22. Agren JJ, Valve R, Vidgren $H$, Laakso M, Uusitupa M. Postprandial lipemic response is modified by the polymorphism at codon 54 of the fatty acid binding protein 2 gene. Arterioscler Thromb Vasc Biol. 1998; 18(10):1606-10.

23. Dane-Stewart CA, Watts GF, Barrett PH, Stuckey BG, Mano TC, Martins IJ, et al. Chylomicron remnant metabolism studied with a new breath test in postmenopausal women with and without type 2 diabetes mellitus. Clin Endocrinol. 2003; 58(4):415-20.

24. Large V, Peroni O, Letexier D, Ray H, Beylot M. Metabolism of lipids in human white adipocyte. Diabetes Metab. 2004; 30(4):294-309.

25. Lewis GF. Fatty acid regulation of very low density lipoprotein production. Curr Opin Lipidol. 1997; 8(3):146-53.

26. Austin MA. Triglyceride, small, dense low-density lipoprotein, and the atherogenic lipoprotein phenotype. Curr Atheroscler Rep. 2000; 2(3): 200-7.

27. Marcil M, O'Connell B, Krimbou L, Genest JJr. High-density lipoprotein: multifunctional vanguard of the cardiovascular system. Expert Rev Cardiovasc Ther. 2004; 2(3):417-30.

28. Nakamura MT, Nara TY. Structure, function, and dietary regulation of delta6, delta5, and delta9 desaturases. Annu Rev Nutr. 2004; 24:345-76.

29. Kinsella JE, Broughton KS, Whelan JN. Dietary unsaturated fatty acids: interactions and possible needs in relation to eicosanoid synthesis. J Nutr Biochem. 1990; 1(3):123-41.

30. Lands WEM. Long-term fat intake and biomarkers. Am J Clin Nutr. 1995; 61(Suppl):721S-5.
31. Wolk A, Vessby B, Ljung H, Barrefors P. Evaluation of a biological marker of dairy fat intake. Am J Clin Nutr. 1998; 68(2):291-5.

32. Wolk A, Furuheim M, Vessby B. Fatty acid composition of adipose tissue and serum lipids are valid biological markers of dairy fat intake in men. J Nutr. 2001; 131(3):828-33.

33. Popp-Snijders C, Blonk MC. Omega-3 fatty acids in adipose tissue of obese patients with non-insulin-dependent diabetes mellitus reflect long-term dietary intake of eicosapentaenoic and docosahexaenoic acid. Am J Clin Nutr. 1995; 61(2):360-5.

34. Ma J, Folsom AR, Shahar E, Eckfeldt JH. Plasma fatty acid composition as an indicator of habitual dietary fat intake in middle-aged adults. The Atherosclerosis Risk in Communities (ARIC) Study Investigators. Am J Clin Nutr. 1995; 62(3):564-71.

35. Smedman AE, Gustafsson IB, Berglund LG, Vessby $B O$. Pentadecanoic acid in serum as a marker for intake of milk fat: relations between intake of milk fat and metabolic risk factors. Am J Clin Nutr. 1999; 69(1):22-9.

36. Ascherio A. Epidemiologic studies on dietary fats and coronary heart disease. Am J Med. 2002; 113(Suppl 9B):9S-12.

37. Baylin A, Kabagambe EK, Ascherio A, Spiegelman D, Campos H. High 18:2 trans-fatty acids in adipose tissue are associated with increased risk of nonfatal acute myocardial infarction in costa rican adults. J Nutr. 2003; 133(4):1186-91.

38. Baylin A, Kabagambe EK, Siles X, Campos $H$. Adipose tissue biomarkers of fatty acid intake. Am J Clin Nutr. 2002; 76(4):750-7.

39. Garland M. The relation between dietary intake and adipose tissue composition of selected fatty acids in US women. Am J Clin Nutr. 1998; 67(1): 25-30.

40. Malcom GT, Bhattacharyya AK, Velez-Duran M, Guzman MA, Oalmann MC, Strong JP. Fatty acid composition of adipose tissue in human: differences between subcutaneous sites. Am J Clin Nutr. 1989; 50(2):288-91.

41. Folch J, Lees M, Stanley GHS. A simple method for the isolation and purification of total lipids from animal tissues. J Biol Chem. 1957; 226(1): 497-509.

42. Houwelingen ACV, Kester ADM, Kromhout D, Hornstra G. Comparison between habitual intake of polyunsaturated fatty acids and their concentrations in serum lipid fractions. Eur J Clin Nutr. 1989; 43:11-20.

43. Ratnayake WM. Overview of methods for the determination of trans fatty acids by gas 
$500 \mid$ J.S. vAZ et al.

chromatography, silver-ion thin-layer chromatography, silver-ion liquid chromatography, and gas chromatography/mass spectrometry. J AOAC Int. 2004; 87(2):523-39.

44. Gutnikov G. Fatty acid profiles of lipid samples. J Chromatogr B Biomed Appl. 1995; 671(1-2): 71-89.

45. Ackman RG. Application of gas-liquid chromatography to lipid separation and analysis: qualitative and quantitative analysis. In: Chow CK. Fatty Acids in Foods and their Health Implications. 2nd ed. New York: Marcel Dekker; 2000. p.47-65.

46. Wolff RL, Precht D. A critique of 50-m CP-Sil 88 capillary columns used alone to assess trans- -unsaturated FA in foods: the case of the TRANSFAIR Study. Lipids. 2002; 37(6):627-9.

47. Cruz-Hernandez C. Methods for analysis of conjugated linoleic acids and trans-18:1 isomers in dairy fats by using a combination of gas chromatography, silver-ion thin-layer chromatography/gas chromatography, and silver-iron liquid chromatography. J AOAC Int. 2004; 87(2):545-62.

48. Leonard AE, Pereira SL, Sprecher H, Huang YS. Elongation of long-chain fatty acids. Prog Lipid Res. 2004; 43(1):36-54.

Recebido em: 21/12/2004 Versão final reapresentada em: 19/9/2005 Aprovado em: 26/10/2005 